
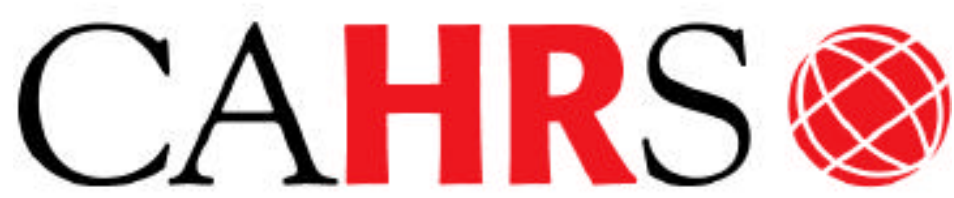

Center for Advanced Human Resource Studies
CAHRS / Cornell University 187 Ives Hall

Ithaca, NY 14853-3901 USA

Tel. 607 255-9358

www.ilr.cornell.edu/CAHRS/

WANGPAPRSPPIS

\title{
Dispositional Influences on Attributions Concerning Absenteeism
}

\author{
Timothy A. Judge \\ Joseph J. Martocchio
}

Working Paper 9 4- 03 


\title{
Dispositional Influences on Attributions Concerning Absenteeism
}

\author{
Timothy A. Judge \\ Center for Advanced Human Resource Studies \\ New York State School of Industrial and Labor Relations \\ Cornell University
}

\begin{abstract}
Joseph J. Martocchio
Institute of Labor and Industrial Relations

University of Illinois at Urbana-Champaign

Working Paper \#94-03

Running Head: DISPOSITIONS AND ABSENCE ATTRIBUTIONS

http://www.ilr.cornell.edu/cahrs

This paper has not undergone formal review or approval of the faculty of the ILR School. It is intended to make results of Center research, conferences, and projects available to others interested in human resource management in preliminary form to encourage discussion and suggestions.
\end{abstract}




\begin{abstract}
Because the degree to which absenteeism is within or beyond an employee's control is a significant yet unresolved issue in the absence literature, it is important to understand the factors which influence employees' attributions about the causes of absence events. As a result of recent research suggesting that personality variables are important influences on work attitudes and behaviors, the present study took a dispositional approach in investigating the predictors of employee absence attributions. Using data collected from three sources, between-subjects analyses suggested a number of dispositional influences on absence attributions. Within-subjects analyses suggested that the factors leading to external attributions vary widely across individuals.
\end{abstract}




\section{Dispositional Influences on Attributions Concerning Absenteeism}

Employee absenteeism has received substantial attention by human resource management and industrial relations scholars and practitioners (see Martocchio \& Harrison, 1993; Rhodes \& Steers, 1990). Management's interests center on minimizing the potential work place disruptions absence may cause (Goodman \& Atkin, 1984) and the significant financial cost of absence (Martocchio, 1992). Labor's interests center on promoting progressive disciplinary procedures that provide those who are absent with an opportunity to mitigate the effects of the factors that result in their absence (Ballagh, Maxwell, \& Perea, 1987), and to prevent a breach of an employee's duty to attend work regularly (Rosenthal, 1979).

Although concerned with absence for different reasons, both labor and management have focused on what they can do to lower voluntary absence levels, or absence that is presumed to be within an employee's control (Ballagh et al., 1987). Often, these efforts begin with the identification of employees whose absence is higher than levels sanctioned by organizational policy. Unfortunately, efforts to reduce voluntary absence may be ineffective. One of the reasons for this potential ineffectiveness is that it is difficult to infer from operational measures whether absence is voluntary or involuntary. Typically, both researchers and practitioners have indexed absence as the frequency of contiguous days absent regardless of the duration of each episode, or the number of days absent for a given period (Chadwick-Jones, Brown, Nicholson, \& Sheppard, 1971), and these measures are based on data extracted from personnel records (Martocchio \& Harrison, 1993). However, these measures have been shown to be contaminated because measures of purported voluntary absence spuriously assess involuntary absence, and vice versa (Hammer \& Landau, 1981). Criterion contamination is exacerbated by the process of classification that takes place when the absent employee or clerk who logs absence occurrences decides how to categorize these events for inclusion in the personnel files (Atkin \& Goodman, 1984; Hammer \& Landau, 1981; Smulders, 1980).

Ultimately, these problems of inference have lead researchers to conclude that the meaning of absence (i.e., whether voluntary or involuntary) rests with the employee (Hammer \& Landau, 1981), and the meaning of a voluntary absence is likely to vary within individuals across time and settings (Johns \& Nicholson, 1982). With these considerations in mind, researchers recently have begun to model the employee's decision to be absent (Hackett, Bycio, \& Guion, 1989; Martocchio \& Harrison, 1993; Martocchio \& Judge, in press-a). These efforts are based on the assumption that an employee consciously makes decisions to be absent, and such decisions predict absence occurrences (see Martocchio \& Harrison, 1993). An alternate view is that any absence episode is perhaps the result of habit or some unconscious 
decision that is motivated by an obligation to constituents outside the work place (e.g., taking care of an elderly relative) rather than by a conscious decision process (Johns \& Nicholson, 1982; Nicholson, 1977). Notwithstanding these views, little is known about the attributions employees make concerning whether absence-inducing events were within or outside their control (i.e., involuntary versus voluntary), and the relative importance of these events.

Conceptually, this approach to examining employee attributions about absence necessitates a within-subjects design because such a design enables researchers to assess whether absence events are phenomenologically unique to individuals (i.e., whether absence may mean different things to different people at different times [Johns \& Nicholson, 1982]). Using a within-subjects design, prior research has provided support for Johns and Nicholson's argument that the factors that lead to an employee's decision to be absent as well as the relative importance of these factors are not the same for all individuals (Hackett et al., 1989; Martocchio \& Judge, in press-a). Moreover, to more fully capture the meaning of absence to individuals, Nicholson (1977; Johns \& Nicholson, 1982) maintains that stable differences between individuals may be related to the absence phenomenon, and the attributions employees make concerning the cause of absence. To date, there has been no systematic investigation of dispositional factors that are likely to lead to differences in the interpretations employees make of absence occurrences.

The purpose of this study is to provide a within-subjects assessment of the attributions employees make for the factors that contribute to a decision to be absent from work. This method gets closer to discerning the meaning of absence for individuals, specifically, the extent to which an employee views an absence episode as within or outside his or her control, and complements existing research (Hackett et al., 1989; Martocchio \& Judge, in press-a) by shedding light on the extent to which an employee attributes absence-inducing events to factors within or outside his or her control. Our study is guided partly by prior theory and empirical evidence, and is partly exploratory in nature as there is relatively little research on this topic. The confirmatory part of this study links dispositional characteristics to absence attributions based on those dispositions believed to be theoretically relevant. In the exploratory section of the paper, a cluster analysis of absence attributions is used to assess the degree to which the perceived voluntary or involuntary nature of absence has different meanings for individuals. We used these different strategies to provide as much information as possible about the main effects of within- and between-subjects variables on the attributions employees make for the factors that contribute to a decision to be absent from work. 


\section{Hypotheses}

\section{Absence-Inducing Events}

Based on prior research on the antecedents of absence decisions (Hackett et al., 1989; Martocchio \& Judge, in press-a; Morgan \& Herman, 1976; Nicholson \& Payne, 1987), we hypothesized that attributions about an absence occurrence would be influenced by several absence-inducing events. These hypothesized events are the following: (a) personal illness; (b) kinship responsibilities; (c) pressing work demands; and (d) break in the work week. The rationale for the influence of these factors follows.

Personal illness. Nicholson and Payne (1987) reported results of home interviews of a variety of employees who were asked to make attributions of their prior absences as well as potential future absences. They found that the vast majority of individuals attributed potential future absence to factors beyond their personal control, specifically, to illness, rather than to events within their own control, such as leisure activities. This finding was subsequently replicated (Hackett et al., 1989; Martocchio \& Judge, in press-a). Nicholson and Payne (1987) concluded that attributing absence to medical illness is consistent with evolving social beliefs about what constitutes acceptable reasons for absence in a particular context. This conclusion fits well with research which showed that medical absence was systematically related to work and nonwork motives (Rushmore \& Youngblood, 1979).

Smulders (1980) suggested that absence is one element of a "sick role" (viz., Parsons, 1952), a temporal process in which an individual moves from a "well" state to a state of illness, to a coping process, and finally a return to a "well" state. In particular, Smulders (1980) argued that an absentee makes many, sometimes unconscious, decisions to enact the "sick role" that are under the influence of external circumstances (e.g., the attitudes and opinions of relatives and medical professionals as well as sickness benefits offered by the employer and the job situation). An employee is more willing to return to his or her job when working conditions improve or upon the advice of his or her physician (Smulders, 1980).

Finally, it is likely that absence often is attributed to illness because illness often actually does prohibit attendance. This conclusion is supported by research linking objective reports of employee health to absenteeism (Leigh, 1991; Tucker, Aldana, \& Friedman, 1990). The above arguments suggest that illness will be a very salient attribution regarding the cause of absence.

Hypothesis 1: The presence of personal illness will lead to external attributions regarding the cause of absence. 
Kinship responsibilities. When an employee's kinship responsibilities are pressing (e.g., a child or other family member is very ill), this person will choose between staying away from work to deal with the demands, or attending work by leaving the responsibility with a spouse or other family member. If an employee cannot rely on others to manage a particular episode associated with kinship responsibilities, then he or she would be absent (Martocchio \& Judge, in press-a). In this case, it is logical to expect that the employee would attribute absence to factors outside personal control. On the other hand, if an employee can rely on others, yet chooses to be absent from work, then it is still in his or her best interest to attribute the absence episode to factors outside personal control, particularly if this employee faces discipline due to absence. Often, kinship responsibilities are deemed as a mitigating or extenuating circumstance by arbiters and employers in both nonunion and union settings in absence disciplinary procedures, and such circumstances usually cause the employer to lessen the penalty (Ballagh et al., 1987). Therefore, employees are likely to attribute an absence episode that is due to kinship responsibilities to factors beyond their personal control.

Hypothesis 2: The presence of kinship responsibilities will lead to external attributions regarding the cause of absence.

Pressing work demands. Consistent with Morgan and Herman's (1976) analysis based on expectancy theory, an employee is less likely to be absent from work when there are major demands that consist of a heavy work load and pressing deadlines. Recently, support has been found for this proposition (Martocchio \& Judge, in press-a). When absent during high-demand work periods, an employee is more likely to fall behind in his or her responsibilities. Falling behind may result in negative outcomes such as a reprimand or poor performance evaluation because absence can be thought of as a breach of an employee's duty to attend work regularly (Ballagh et al., 1987). Obviously, the consequences of breaching one's duty to work are likely to be more significant when work demands are substantial. Thus, when work demands are high and an absence occurs, an employee should be more willing to attribute the episode to factors beyond personal control than when work demands are not heavy. Moreover, retrospective rationality (Salancik \& Pfeffer, 1978) suggests that when absent, an employee might conclude, "I was absent despite having pressing work, so it must have been beyond my control."

Hypothesis 3: The presence of pressing work demands will lead to external attributions regarding the cause of absence.

Break in the work week. Another factor that is expected to influence absence is when absence occurs in relationship to scheduled time off such as the "weekend" (Chadwick-Jones, Brown, Nicholson \& Sheppard, 1971). Martocchio and Judge (in press-a) found that employees 
were more likely to be absent from work on days adjacent to scheduled time off than during the course of contiguous work days, and we expect that the attributions employees make will depend upon whether absence occurs within a series of contiguous scheduled work days, or just prior to or following scheduled days off. Our rationale comes from the view that absence occasionally facilitates stress reduction for employees (Staw \& Oldham, 1978). It is possible that employees would attribute absence that occurs during the course of adjacent work days to factors outside their personal control, recognizing the need to take time off to regain perspective. In addition, employees would be likely to attribute absence that occurs in the middle of the work week to external factors because employees wish to avoid work disruptions that would occur.

Hypothesis 4: Absences that result in a break in the work week will lead to external attributions regarding the cause of absence.

\section{Dispositional Influences}

Below we advance several hypotheses that relate dispositional factors to attributions employees make about the causes of absence. To date, there is insufficient conceptual research on the influence of dispositional factors on work outcomes in general (Judge, 1992), and employee absence in particular (Martocchio \& Harrison, 1993). Thus, our selection of dispositional variables was guided by an a priori assessment of factors that we felt would fit well with the conceptualization of absence that we presented earlier. These factors include: (a) Protestant Work Ethic, (b) self-deception, (c) negative affectivity, (d) tendency to make excuses, two aspects of locus of control (e) life controlled by chance and (f) internality, (g) learned helplessness, and (h) health complaints.

Protestant Work Ethic. Values are general modes of behavior representing what an individual should or ought to exhibit (Rokeach, 1973). The Protestant Work Ethic (Blood, 1969) has been one of the most commonly studied work values. Individuals who endorse the Protestant Ethic believe in the intrinsic value of hard work, the merit of achievement in society, and the necessity of short-term sacrifice (Blood, 1969). Although it is unclear whether or not work values are truly dispositional in nature, work values are relatively stable (Judge \& Bretz, 1992), and evidence suggests that the Protestant Work Ethic is dispositional in nature (Mirels \& Garrett, 1971). Because being absent from work implies a failure in one's work role obligations, individuals who endorse the Protestant Ethic should be more likely to attribute absence to their own failings rather than to contextual factors. For example, one of the best items Mirels and Garrett (1971) studied is, "People who fail at a job usually have not tried hard enough" (p. 41). This suggests that pro Protestant Work Ethic individuals have little tolerance for failure at work 
(such as failing to attend work), and thus more likely attribute absence to failings of the person rather than the situation. Thus,

Hypothesis 5: Protestant Work Ethic will negatively influence external attributions regarding the cause of absence.

Self-deception. Self-deception refers to the tendency to have honestly-held but positively biased views of oneself (Paulhus, 1986). Research shows that individuals disposed to engage in self-deception ignore minor criticisms, discount failures, and avoid negative thoughts (Sackeim \& Gur, 1979). Not surprisingly, research shows that self-deceivers are less likely to be depressed than other individuals (Paulhus \& Reid, 1991; Roth \& Ingram, 1985; Sackeim \& Gur, 1979). Because self-deception is used to avoid aversive self-confrontation and attributions of failure (Sackeim \& Gur, 1979), the link between self-deception and positive attributions (at the extremes called "positive illusions") is easy to understand (Taylor, 1989). In fact, Sackeim and Gur argued that self-serving attributions, such as the tendency to make external attributions about negative events, may have their basis in self-deception. Furthermore, Roth, Snyder, and Pace (1986) found that individuals with a tendency to engage in self-deception denied negative characteristics that threatened their self-image. This suggests that self-deceivers are likely to make external attributions about absence events to avoid negative self-images. Thus,

Hypothesis 6: Self-deception will positively influence external attributions regarding the cause of absence.

Negative affectivity. According to Watson and Clark (1984), NA reflects individual differences in negative emotionality and self-concept. High NA individuals are likely to be distressed and upset, and view themselves and the world around them negatively. NA is relevant in the case of absence attributions because research has found that depressed or high NA individuals are more realistic and accurate in their judgments (Alloy \& Abramson, 1979). In fact, these authors found that non-depressed (low NA) subjects discounted their true degree of control over negative outcomes but overestimated their degree of control over positive outcomes (the actual degree of control was held constant in their experiments). Given that being absent from work is likely to be viewed negatively by co-workers and supervisors (Goodman \& Atkin, 1984), these findings suggest that high NA individuals will be more likely to attribute absence to factors within their control. Thus,

Hypothesis 7: Negative affectivity will negatively influence external attributions regarding the cause of absence.

Excuse-making-. Snyder and Higgins (1988) defined excuse making as the "motivated process of shifting causal attributions for negative personal outcomes from sources that are 
relatively more central to the person's sense of self to sources that are relatively less central" ( $p$. 23). Since absence from work is likely to be viewed as a negative outcome, it appears likely that employees will be motivated to engage in excusing-making behavior when absent from work. According to Higgins and Snyder (1989), the motivation underlying excuse-making can be as a protection mechanism against threats to self-esteem, or as a form of impression management behavior. While excuse-making is partly driven by contextual factors, individuals also likely differ in their tendencies to make excuses across a wide variety of situations. Thus, we expect that employees who have a tendency to make excuses as a result of absence will be more likely to make external attributions about the causes of absence than employees with a lower tendency to engage in excuse-making behavior.

Hypothesis 8: The tendency to make excuses will positively influence external attributions regarding the cause of absence.

Locus of control: life controlled by chance and internality. Derived from Rotter's (1954) social learning theory, locus of control is a generalized expectancy pertaining to the connection between personal characteristics or actions and experienced outcomes (Rotter, 1966). Specifically, locus of control concerns the tendency to ascribe the cause of events either to oneself or to the external environment. Accordingly, those who attribute control of events to their own behavior or to relatively permanent characteristics are said to have an internal locus of control, while those who attribute control to outside forces are said to have an external locus of control (Rotter, 1966). Since its conception, the locus of control construct has been refined (Lefcourt, 1991). A widely cited refinement is Levenson's (1981) reconceptualization of locus of control as a multi-faceted construct consisting of three factors: powerful others, life controlled by chance, and internality. Levenson's reconceptualization is based on the assumption that an individual can believe in his or her own efficacy while believing at the same time that other powerful persons also are invested with control, or that one can believe in the power of luck or chance happenings and still count on one's own ability to control events. We maintain that the latter two facets, life controlled by chance and internality, are relevant to the prediction of attributions concerning the cause of absence. (Powerful others was not included because the items pertained more to political or hierarchical control rather than control over specific events such as absence.) Life controlled by chance reflects a predisposition about the degree to which a person believes chance typically affects his or her experiences and outcomes. Internality, on the other hand, refers to the degree to which people believe they have control over their own lives. Thus, we anticipate that employees who are of the mind that chance dictates outcomes 
in their lives should attribute the circumstances leading to an absence occurrence to external factors. Moreover, we expect that employees who typically believe they have control over the events in their lives will tend to make internal attributions about the causes leading to absence.

Hypothesis 9a: Employees who account for the occurrence of events in their lives with chance should be more willing to make external attributions for the events that lead to an absence occurrence than employees who tend not to rely on chance explanations.

Hypothesis 9b: Employees who ascribe the occurrence of events in their lives to personal control should be more willing to make internal attributions for the events that lead to an absence occurrence than employees who tend not to ascribe the occurrence of events to personal control.

Learned helplessness. A key tenet of learned helplessness theory (Seligman, 1975) is that people exposed to uncontrollable events ultimately develop a relatively invariant expectation that they do not control events. Serious consequences of these expectations include motivational deficits that are manifested in lower response initiation and lowered persistence, and cognitive deficits that are characterized by an individual's inability to perceive existing opportunities to control outcomes. In its original formulation (Seligman, 1975), learned helplessness theory did not account for individual differences in susceptibility to helplessness. Subsequent research demonstrated that individuals who habitually explain life events by external, unstable, and specific causes will be more likely to experience general and lasting symptoms of helplessness than individuals with the opposite style (Abramson, Seligman, \& Teasdale, 1978). This conclusion has been confirmed by a number of studies using adults (see Peterson \& Seligman, 1984).

We expect that learned helplessness will predict the attributions employees make about the circumstances surrounding an absence occurrence. As indicated earlier, absence can be thought of as a breach of one's duty to work that, as a rule, results in disciplinary actions against the employee (Ballagh et al., 1987). From almost any standpoint, it is reasonable to label this conception of absence as a negative event in as much as the act of being absent (i.e., breach of duty) and the attendant outcomes (i.e., disciplinary action) are considered undesirable. Employees whose explanatory style toward events is characterized by external, unstable, and specific causes are susceptible to helplessness. Accordingly, helpless employees, in turn, are more likely to attribute the occurrence of negative events (including absence) to reasons beyond their control. Thus, 
Hypothesis 10: Employees who exhibit patterns of learned helplessness should be more willing to make external attributions for the events that lead to an absence occurrence than employees who do not exhibit such tendencies.

Health complaints. As stated earlier, personal illness has been found to be among the most salient reasons for absence that employees advance (Hackett et al., 1989; Martocchio \& Judge, in press-a; Morgan \& Herman, 1976; Nicholson \& Payne, 1987). Researchers have concluded that personal illness constitutes a socially acceptable reason for absence in a particular context (Rushmore \& Youngblood, 1979; Smulders, 1980). In those studies, personal illness per se has been addressed at a general level such that the phrase "personal illness" has been advanced by employees as a statement of cause of absence. Left relatively unexplored has been the question of whether differences among employees in their experience of physical symptoms of illness (e.g., excessive fatigue, headaches, backaches) may influence the attributions they make about an absence occurrence. Although health and the reporting of health complaints is only quasi-dispositional in nature, health is partly genetically-based, and the reporting of health complaints has been viewed from a dispositional perspective (Kobasa, 1979). It is reasonable to expect that as the number of physical symptoms mounts, it may be increasingly difficult, or impossible, for an employee to attend work. Coupled with the acceptability of personal illness as a cause of absence, we advance the following hypothesis.

Hypothesis 11: Employees who report health problems should be more willing to make external attributions for the events that lead to an absence occurrence than employees whose health complaints are fewer.

\section{Control Variables}

Additional factors were expected to predict attributions about the cause of absence based on prior theory and research. Organizational tenure (Hackett, 1990), age (Martocchio, 1989), actual kinship responsibilities the employee currently has in general (versus what they may experience on a particular day) (Steers \& Rhodes, 1978), and occupation and race (Rhodes \& Steers, 1990) represent demographic factors that many researchers have used as proxies for the possible attributional processes engaged by employees to explain their absences (Nicholson, 1977; Nicholson \& Payne, 1987). Since older and more tenured workers are absent less (Hackett, 1990; Martocchio, 1989), and thus may be less likely to excuse absence, we expected organizational tenure and age to negatively influence external attributions. Because actual kinship responsibilities are associated with increased absence rates and are often attributed as beyond the employees control, we expected kinship responsibilities to 
positively influence external attributions. Finally, occupational status and race were instituted as a control because absence rates have been found to vary widely by occupation and by race (Rhodes \& Steers, 1990). However, we do not make a specific prediction because the nature of the relationships is inconclusive.

\section{Method}

\section{Setting, Subjects, and Procedure}

Surveys were administered to a stratified random sample of employees of a large university located in the Midwest. Subjects occupied a wide range of service jobs in the university, ranging from clericals to construction workers to administrators. Average age of respondents was 46.7 years. Sixty-eight percent of respondents were female, and $84 \%$ were married. Thirty-five percent of respondents had one or more children under 18 years of age. Whites constituted $95 \%$ of the respondents. Average salary of respondents was $\$ 23,095$. Thirty-six percent of respondents had a high school diploma, 43\% had an associate's degree or completed some college work, and $21 \%$ had at least an undergraduate degree.

Surveys were mailed to employees through campus mail. Participants were told in a cover letter that individual responses were completely confidential, and were promised a $\$ 15$ honorarium in return for completing the survey. Subjects also were asked to sign an informed consent form. Subjects were sampled from all departments within the university. From a potential pool of 433 respondents, 138 useable surveys were returned, representing a response rate of $32 \%$. In order to compare the degree to which the sample of respondents was representative of the population, respondents and non-respondents were compared with respect to information contained in the university's archival records (age, organizational tenure, race, gender, salary, and job type). No significant differences were found, suggesting that respondents were representative of the larger population of employees.

In an effort to minimize self-report bias, several aspects of the focal employee's disposition was evaluated from the perspective a "significant other" (i.e., a spouse or family member). The choice of which variables to measure from the perspective of a significant other rested on two considerations: (1) the need to keep the significant other survey brief; (2) a somewhat subjective judgment of which constructs would be measured most appropriately from the perspective of the significant other, accomplished by examining the items within each dispositional measure. The relationship of the significant others to the respondents was as follows: spouse $=74 \%$; close friend $=19 \%$; sibling $=3 \%$; parent=4\%. In a further effort to reduce reliance on self-report data, relevant archival data (i.e., age, tenure, etc.) were obtained from the 
university personnel records. These multiple sources of data should yield a more accurate, complete, and unbiased estimate of the core constructs.

\section{Research Design}

A mixed experimental design was used, incorporating both within-subjects and between-subjects components (Keppel, 1982). The factors we manipulated were illness; kinship responsibilities, pressing work demands, and break in the work week. Each factor, with the exception of the illness factor, contained two levels (i.e., the factor was present or not). The illness factor contained three levels (i.e., illness was not a factor, minor illness, and major illness). The four within-subjects independent variables were completely crossed which permits assessment of the independent effects of each factor on attributions regarding the cause of absences. Crossing the factors resulted in $24(2 \times 2 \times 2 \times 3)$ scenarios which contained all possible combinations of the independent variables. As a means of assessing reliability of the dependent variable, six scenarios were replicated. In order to minimize order effects, the scenarios were presented in the survey in random order and the factors were presented in random order within each scenario. Each participant was asked to read each description as a set of factors that he or she might encounter on a scheduled work day. An example of a scenario is provided below.

Assume that on a day that you are scheduled to work you have the following event(s) occurring...

* $\quad$ You are in the middle of your scheduled work week. It's been 2 days since you have had time off from work, and it will be 2 days before you have some scheduled time off.

* You need to take care of your children or have other family responsibilities.

* You have a heavy work load or an important deadline at work you must meet.

* You do not feel well today, and are physically unable to take on your normal duties.

\section{Measures}

External attribution about the cause of absence. Belief about whether the absence occurrence depicted in each scenario was due to factors external to employees (e.g., beyond the employees' control) was operationalized in the following manner: "If you were absent given the above circumstances, would this absence be within or beyond your control?" A seven-point Likert-type scale was used, and it was anchored by $1=$ totally within my control to $7=\underline{\text { totally }}$ 
beyond my control. Reliability of the dependent variable was calculated by computing reliability coefficients for each of the six replicated scenarios, and then averaging the six reliability coefficients. The resulting reliability estimate of this measure was .87 .

Life controlled by chance and internality. The personality trait of locus of control traditionally has been measured by Rotter's (1966) scale. However, Rotter's scale has come under scrutiny because of its unidimensional conceptualization, its inherent social desirability bias, and difficulties created by its forced-choice response format (Lefcourt, 1991). Accordingly, Levenson's (1981) Internality, Powerful Others, Chance (IPC) scale was chosen to measure these factors. The IPC reflects three dimensions of locus of control, Internality and Chance (both of which were defined earlier), and Powerful Others (the degree to which people believe other person's control events in their lives). Because it did not seem relevant for the purposes of this study (it seemed to measure political control more than personal control), the Powerful Others subscale was not included in the analysis. The focal employees evaluated eight statements regarding their internality (e.g., "My life is determined by my own actions"). The significant others of the respondents rated the degree to which they felt the focal employees would endorse eight statements reflecting chance ("He believes that when he makes plans, he is almost certain to make them work"). The reliability of the internality subscale was .72 and the reliability of the chance subscale was .77 .

Learned helplessness. Learned helplessness was measured by the Attributional Style Questionnaire (ASQ; Peterson, Semmel, von Baeyer, Abrahamson, Metalsky, \& Seligman, 1982). The ASQ measures the stable tendency of people to make attributions that signifies that they are helpless to the world around them. The ASQ presents individuals with twelve hypothetical scenarios (e.g., "You meet a friend who acts hostile toward you," "You become very rich"). Respondents then are asked to indicate whether each evident is within or beyond their control ( 1 =totally due to other people or circumstances to 7 =totally due to me). Research has demonstrated that the ASQ possesses moderate internal consistency and test-retest reliabilities, and validity (Peterson \& Seligman, 1984). In the present study, the reliability of the ASQ was .79.

Negative affectivity. Negative affectivity was measured using the NA portion of the Positive and Negative Affect Schedule (PANAS; Watson, Clark, \& Tellegen, 1988), a 10-item measure of an individual's tendency to experience aversive emotional states. As recommended by Watson et al. (1988), the NAS was used to measure trait-NA versus state-NA by using long-term instructions. Watson et al. reported that the PANAS displayed high degrees of reliability and convergent and discriminant validity. Furthermore, Watson et al. reported that the 
NAS was stable over time ( $r=.71$ over a 2-month period). Judge and Bretz (1993) also found that the NA Schedule was reasonably stable over a 6-month period (corrected $r=.71$ ). For the NAS in the present study, the coefficient alpha was .85 .

Protestant Work Ethic. Protestant Work Ethic was measured by the scale developed by Blood (1969). This scale asks individuals to respond to eight statements about their general beliefs (e.g., "Hard work makes a person better"). Results by Blood suggest that the Protestant Ethic scale possesses favorable psychometric properties. In the present study, the scale was modified in two ways: (1) since the scale was completed by significant others rating the focal employee, the scale was modified by adding a stem that preceded the eight statements (e.g., "My significant other believes that ..."); (2) wording was made gender-neutral (i.e., "a man" was changed to "a person"). The alpha of this scale was .62.

Self-deception. Self-deception was measured with Paulhus' Balanced Inventory of Desirable Responding (BIDR; Paulhus, 1984), which assesses the tendency to give oneself reports that are positively biased (e.g., endorsing a statement such as, "I never regret my decisions," "I am a completely rational person"). Overall, this 20 -item scale appears to have desirable psychometric properties and converges with other measures of self-deception (Paulhus, 1991). In the present study, the reliability of the self-deception subscale was .71. Health complaints. On the basis of a scale contained in the Quality of Employment Survey (QES; Quinn \& Staines, 1979), a scale was formed consisting of items where significant others indicated if the focal employee had experienced a number of physical conditions in the past year, including back pain, stomach problems, headaches, excessive fatigue, and insomnia (Judge \& Watanabe, 1993). The frequency of occurrence of each

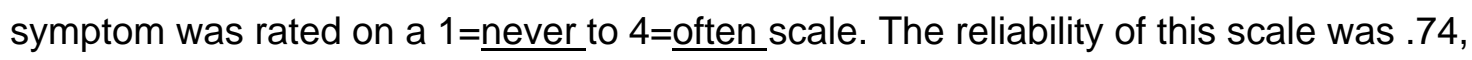
confirming that health problems are often interrelated (Bultena \& Oyler, 1971).

Excuse-making. Five items assessed the extent to which an employee has a tendency to makes excuses for absence. Participants responded to a five-point Likert scale anchored by

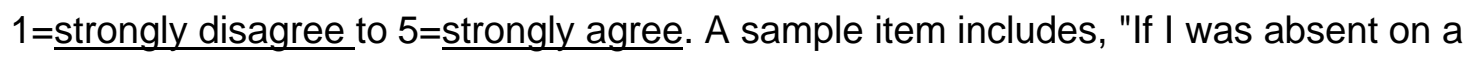
particular day due to some reason other than illness, as an excuse I might tell my supervisor I was ill. " The reliability estimate for this scale was . 84.

Demographic variables. Organization tenure, age, gender, and occupation were taken from data contained in the university's archival records. Information on number of dependents was collected from a specific question on the focal employee survey. 


\section{Analysis}

Between-subjects analysis. The data set used for the analysis was constructed by duplicating individual difference variables and then appending these to the 4 within-subject manipulations and corresponding attributions (30 for each individual). Conceptually, duplicating between-subject factors is appropriate because a between-subject factor can affect the respondent's reaction to each scenario (Judge \& Bretz, 1992). For example, internality may influence an absence attribution each time an individual is presented with a hypothetical choice, much like internality could influence absence attributions over time (e.g., each time an individual is confronted with an actual choice and subsequent attribution). Statistically, this is appropriate because each reaction to a scenario is an independent event, and each event becomes a dependent variable (Hays, 1981). Because each of the 138 respondents reacted to 30 scenarios, the sample size used for the analysis was 4,140 (30 x 138), less cases deleted due to missing values.

The problem created when duplicating variables is that observations are no longer independent from one another. This means that there will likely be a positive correlation between error terms (autocorrelation), violating an assumption of ordinary least squares (OLS) regression (Kennedy, 1985). The consequences of this violation are that while OLS is still an unbiased estimator of regression coefficients, it is no longer the maximum efficiency estimator, nor is it an unbiased estimator of the variance of regression coefficients (standard errors). Given the problem of autocorrelation, OLS estimation of standard errors is not appropriate. Therefore, generalized least squares (GLS) was used to estimate the effect of the absence-inducing events and dispositions on attributions concerning absence. GLS produces unbiased estimates of regression parameters and error terms, and thus is well-suited to deal with autocorrelated errors (Hanushek \& Jackson, 1977).

Within-subjects analyses. OLS regression analysis was used to assess the effects of the linear combination of the four independent factors related to attributions concerning absence as well as the individual effects. Orthogonal contrast coding was used (Cohen \& Cohen, 1983). One regression equation was calculated for each participant.

In order to exploit fully the within-subjects design of the study, we investigated the degree to which absence attributions have different meaning for individuals using a hierarchical clustering procedure. Ward's (1953) procedure was used as the clustering method because research has suggested that Ward's procedure performs at least as well as any other clustering method (Milligan, 1980). The procedure used as input the standardized regression weights of the four within-subjects factors for each of the 138 subjects. It then iteratively combined these 
weights and computed an error index based on the sum of the squared deviations between each beta weight for each pair of individuals, divided by the number of individuals in the group. The clusters consisted of those individuals who, when combined together, generated the lowest squared deviation (the least error).

For example, the procedure began by forming 137 groups from the 138 subjects by combining the two individuals who generated the smallest summed squared deviation between their four beta weights. The procedure continued until all individuals were combined into one group. The optimal number of clusters is suggested by the point in this iterative process where the largest relative increase in the error index occurs.

Although information regarding clusters of individuals provides useful information about the degree to which the factors that influence attributions concerning absence have different meaning for individuals, it is also important to understand the factors that may differ between individuals in different clusters. In order to ascertain which factors differentiated individuals in their absence attributions, one-way analysis of variance was used to determine the degree to which variation in these factors varied as a result of cluster membership. Discriminant analysis often has been used to predict cluster membership, but conducting a discriminant analysis on the basis of cluster analysis results is inadvisable (G. Milligan, personal communication, June $26,1991)$. In this case, the between-subjects variables used as influences on absence attributions, and several others variables that we saw as potentially relevant (age, race, number of dependents, occupation, organization tenure, penalties for absence) were used to compare the clusters.

\section{Results}

Table 1 shows the means, standard deviations, and intercorrelations of variable used in the analysis. Table 2 displays the results of the regression analysis. Among the control variables, race, organizational tenure, and age were significantly related to absence attributions. Neither the number of dependents nor occupation predicted attributions about absence. The results for the influence of events on the attributions made for absence (i.e., within-subjects) are presented followed by the results for the influence of dispositional factors (i.e., between-subjects variables) on absence attributions.

-Insert Tables 1 and 2 About Here- 


\section{Between-Subjects Results: Test of the Hypotheses}

Absence-inducing events. Hypotheses 1 and 2 were supported. As predicted, the presence of personal illness lead to external attributions regarding the cause of absence (Hypothesis 1). Consistent with Hypothesis 2, the presence of kinship responsibilities lead to external attributions regarding the cause of absence. Contrary to our expectations, hypotheses 3 and 4 were not supported. The regression coefficients for pressing work demands, and break in the week were not statistically significant, indicating that neither work demands nor break in the work week influenced attributions about absence.

Dispositions. All hypotheses regarding the influence of dispositions on the attributions made about the cause of an absence occurrence received support (Table 2). Specifically, individuals who had an external locus of control (believed their life was controlled by chance and had low internality), who did not endorse the Protestant Work Ethic, who were self-deceivers, who displayed learned helplessness, had low NA, reported more health complaints, and had a tendency to make excuses, were more likely to make external attributions about a particular absence event than were individuals who had the opposite pattern of traits. It should be noted that the variance explained by each of these traits was relatively small (in most cases less than $1 \%$ ); cumulatively the dispositional variables explained $4.4 \%$ of the variance in absence attributions.

\section{Within-Subjects Results}

Within-subjects regressions. As indicated earlier, the within-subjects regression analysis conducted for each participant yielded 138 equations. The results from these regressions suggested wide variation in the extent to which the linear combination of within-subjects factors predicted absence attributions for each participant $\left(\underline{R}^{2}\right.$ ranged from .02 to .82$)$. Furthermore, the effects of each of the four variables on attributions varied across the subjects. The percentage of coefficients that were statistically significant (i.e., $\underline{p}<.05$ ) for each within-subjects factor was as follows: personal illness $=72 \%$; kinship responsibilities $=51 \%$; work demands $=15 \%$; and break in the week $=7 \%$. The percentage of significant coefficients were not always in the predicted direction. The percentage of significant coefficients in the predicted direction by variable was as follows: personal illness $=89 \%$; kinship responsibilities $=90 \%$; day of the week $=60 \%$; and pressing work $=76 \%$. All of these analyses suggest substantial individual differences in the attributions made as a result of absence.

Cluster analysis results. The error index, computed as described earlier, for the four most internally similar clusters was 147,217 . The error index for the three most similar clusters was 187,637 . This represents a $40,420(27 \%)$ increase in the error index. Up to that point, the 
largest increase in the error index was 14,539 (13\%). Thus, the results suggested that four was the optimal number of clusters. Based on the four clusters identified by the hierarchical clustering procedure, each individual was classified into one of the four groups. In order to interpret the meaning of the clusters, regressions of the within-subjects factors on absence attributions were calculated for each cluster. These results are reported in Table 3.

-Insert Table 3 About Here-

The regression weights and coefficients of determination in Table 3 demonstrate differences between the clusters. While interpretation of the clusters is subjective, in this case interpretation seemed relatively straightforward. Cluster $1(n=30)$, where illness and work demands exerted significant but relatively weak influences on absence attributions, was labeled as "illness and work demands weak." For these individuals, illness and pressing work were the only significant influences on absence attributions. The second cluster $(n=62)$, where kinship responsibilities exerted a significant but relatively weak effect on attributions and illness exerted a moderately strong effect on absence attributions, was labeled "illness moderate, kinship responsibilities weak." For these individuals, illness was an important factor in making external attributions, while kinship responsibilities was a significant but weak factor. Cluster $3(n=21)$, where kinship responsibilities and illness were significantly negatively related to external attributions, was labeled the "counter cluster. " Finally, Cluster $4(n=25)$, where illness and kinship responsibilities exerted strong effects on external attributions, was labeled as "illness and kinship responsibilities dominant." Overall, the results indicated that the attributional process as the result of absence is not the same for all individuals. The meaning of the factors in absence attributions different for certain distinguishable groups of individuals.

In order to understand what factors might separate individuals in the clusters, one-way ANOVAs were calculated. Based on the one-way results, pairwise comparisons were made between the groups using the between-subject variables. Alpha inflation was controlled using the Duncan procedure. Table 4 indicates that a number of differences existed between the groups. Individuals in Cluster 1 ("illness and work demands weak") were somewhat more likely to be male, earned the highest salaries, worked the most hours per week, were the oldest and had relatively high levels of education and job tenure, and reported relatively few health complaints. Individuals classified in Cluster 2 ("illness moderate, kinship responsibilities weak") were relatively likely to be male, less likely to be married and work in a white-collar occupation, earned a relatively low salary, work more hours per week, had relatively low levels of education 
and job tenure, were less likely to believe that their life was controlled by chance, than other employees. Those in Cluster 3 ("counter cluster") were most likely to be male and employed in a white-collar profession, worked the fewest hours per week, had the highest level of job tenure, were relatively likely to believe that their life was controlled by chance, reported the most number of health complaints, and were least likely to believe that they would be punished for absence occurrences. Finally, individuals grouped in Cluster 4 ("illness and kinship responsibilities dominant") were most likely to be female, most likely to be married, least likely to be employed in a white-collar occupation, earned the lowest salary, had the lowest level of tenure, had the highest education level, were least likely to believe that their life was controlled by chance, reported the fewest physical symptoms, and believed the penalties for absence were highest of any cluster. Overall, the findings reported in this table suggest that the four clusters are more distinct in terms of their demographic attributes than in terms of their dispositional traits.

-Insert Table 4 About Here-

\section{Discussion}

The focus of this study was on the attributions employees make concerning absenteeism, or the extent to which they attributed an absence event to factors within (i.e., voluntary) or outside (i.e., involuntary) their control. Following the notion that the meaning of absence rests with each employee (Hammer \& Landau, 1981; Johns \& Nicholson, 1982), we were interested in determining whether absence may be phenomenologically unique (the psychological meaning of absence may be different for individuals). Thus, we used a mixed experimental design. Specifically, we conducted a within-subjects assessment of each subject's attributions concerning absence, as well as a between-subjects assessment of the possible differences between individuals in their attributions.

\section{Absence-Inducing Events}

Our analysis of absence-inducing factors revealed that personal illness demonstrated the greatest effects on external attributions concerning absence. One explanation for this finding is that societal norms treat personal illness as an acceptable reason for absence from work (Rushmore \& Youngblood, 1979), and that norms and attitudes facilitate enactment of the "sick role" (Smulders, 1980). An alternative explanation, based on expectancy theory, is that using personal illness as a reason for absence is instrumental to the attainment of motivating outcomes associated with not being at work when scheduled (Morgan \& Herman, 1976). 
Specifically, the organization under study provides individuals with a number of paid absence days that are specifically designated for personal illness. Proof of illness is not required by the organization. These structural factors not only serve to legitimize absence, but also provide incentives for employees to advance personal illness as a reason when they decide to miss work when scheduled. Prior research provides indirect support for these explanations (e.g., Dalton \& Perry, 1981). Finally, attributing absence to factors beyond one's personal control often mitigates the effects of disciplinary actions taken by the employer against the alleged transgressor because it is difficult for an employer to prove whether an "ill" employee was sufficiently ill to perform his or her work duties safely (Ballagh et al., 1987). Of course, we noted earlier that illness often does serve as an absolute barrier to attendance (Leigh, 1991). Thus, the attributions probably reflect the reality of the circumstances as much as individual differences in the tendency to make external attributions.

The next largest effect was for the presence of kinship responsibilities. Historically, attributing absence to kinship demands, whether of dependent elders or children, has been common (Rhodes \& Steers, 1990). As argued earlier, it often is not clear whether kinship was within or outside the control of employees. However, labor force projections suggest that both spouses in a relationship will increasingly assume full-time work outside the home (Wetzel, 1990). Therefore, external attributions may be made for kinship responsibilities as employees often cannot rely on their spouses to deal with these demands.

Contrary to our hypothesis, we did not find an effect for pressing work demands. Our rationale, advanced previously, was based on expectancy theory. Some would not attribute absence to factors within one's personal control, particularly when work demands are high, because this may be considered by the employer as an admission of shirking. On the other hand, others may make internal attributions for absence when work demands are heavy, reasoning that absence is a necessary respite from work in the short-term that may help "charge their batteries" for sustained productivity over the long-run. It is possible that these views were approximately equally represented among our respondents, negating an observed effect for this factor. Clearly, additional research is needed to test these possible explanations.

Finally, our hypothesis for day of the week did not receive support. In fact, the regression coefficient was essentially zero, which suggests that the probability of attributing absence either to internal or external factors based on when absence occurs is not significantly different. Earlier, we presented rationale for an employee making external attributions for absences that result in a break in the work week based on the salutary effects of absence (Staw \& Oldham, 1978). Moreover, we argued that an employee would make internal attributions for absences 
that occur next to scheduled days off because these absences would be less likely to cause a disruption to work. As an alternate rationale, it is possible that an employee would make external attributions for absences that occur next to scheduled days off because it may be more difficult to justify taking time off from work just prior to or after scheduled days off. Future research should assess this conjecture. An alternate rationale is that an employee would make external attributions for absences that occur next to scheduled days off because it may be more difficult to justify taking time off from work just prior to or after scheduled days off.

\section{Dispositional Influences on Absence Attributions}

At a theoretical level, the obtained links between the dispositional factors and attributions concerning absence shed some light on the meaning of voluntary versus involuntary absenteeism. Until now, the literature on absence attributions has been without an examination of theoretically-based antecedents. Thus, this study helps to fill an important gap in the employee absenteeism literature.

The clear support of the hypotheses involving dispositional variables highlight the fact that attributions concerning absence are shaped in different ways, and these differences may manifest themselves in unique patterns of absence events. First, the factors life controlled by chance and learned helplessness suggest a profile of an unfavorable self-concept such that effort is decoupled from the outcome. Individuals high on these dispositions are likely to chronically assign external attributions to absences because they probably believe that their attendance is impeded by any number of agents (e.g., transportation problems). These individuals may not feel they possess the resources necessary to effect positive control over the factors that hinder their attendance (e.g., using public transportation as a backup to using one's car) because they are likely to believe that some other agent (e.g., an ill child) will lead to absence. Moreover, it is unlikely that individuals high in learned helplessness and a belief that life is controlled by chance would take responsibility for their actions simply because they do not believe it is possible.

Second, the factors Protestant Work Ethic, negative affectivity, and internality suggest a profile of positive control such that purposive input is linked to the result. When absent, these individuals will be more apt to claim responsibility. Thus, individuals who are high on these dispositions are likely to make internal attributions because they believe they can effectively manage absence-inducing events, and they will avoid being absent from work because they believe in the intrinsic value of hard work.

Third, the factors self-deception and tendency to make excuses suggest a self-serving profile. Accordingly, absences will virtually always be due to external agents that are considered 
socially desirable (e.g., taking care of an elderly dependent), compared to internal agents that may be considered less socially desirable (e.g., low work motivation). For these individuals, the motive may well be an attempt to "justify" absence in order to mitigate the disciplinary response to the event and the negative self-attributions that may result from being absent (Martocchio \& Judge, in press-b).

As expected, health complaints lead to external attributions. This finding lends support to the notion that there are individual differences in health that influence the attributions employees make concerning absence. The fact that health complaints were assessed independently by a significant other increases confidence in the validity of this result, ruling out a social desirability response by the focal employee. Thus, the results of this study suggest that personal illness has both a dispositional source as well as roots in social norms (e.g., Rushmore \& Youngblood, 1979).

\section{Within-Subjects Regressions}

Our within-subjects analyses revealed that the relative importance of the antecedents of attributions varied substantially. Some factors that positively influenced external attributions for some employees, negatively influenced external attributions for. others. In addition, the average $\underline{\mathrm{R}^{2}}$ showed that the overall combination of these factors varied in importance for each individual. Based on these general findings, absence may have a phenomenologically different meaning for individuals (Johns \& Nicholson, 1982). This conclusion is tentative because while our design permits a detailed within-subject assessment of the factors that shape attributions concerning absence, it falls short of idiographic research strategies that may be better suited for examining phenomenology (Burrell \& Morgan, 1979).

A detailed look at the within-subjects results indicates that personal illness was the most salient antecedent of attributions concerning absence. This finding is consistent with prior research (based on between-subjects designs) which showed that personal illness was used most often as a reason stated by employees for their prior absence as well as a probable reason for future absences from work (Morgan \& Herman, 1976; Nicholson \& Payne, 1987). One explanation for this finding is that societal norms treat personal illness as an acceptable reason for absence from work (Johns \& Nicholson, 1982; Nicholson \& Johns, 1985; Nicholson \& Payne, 1987). A further explanation for this finding is that norms and attitudes facilitate enactment of the "sick role" (Smulders, 1980). Both explanations fit well with relying heavily on personal illness as a reason for prior absence.

These results also indicate that the other absence-inducing events such as kinship, pressing work demands, and break in the work week were significant for a minority of the 
subjects. A growing literature on the antecedents of absenteeism suggests that these factors represent important influences on absence (Hackett et al., 1989; Martocchio \& Judge, in pressa; Morgan \& Herman, 1976; Nicholson \& Payne, 1987.). In fact, the relative effects of these factors in the present study with respect to absence attributions are not unlike those found in prior research. Thus, we believe these results are reasonable.

\section{Cluster Analysis Results}

The results from the cluster analysis suggest that the importance attached to the factors hypothesized to predict absence attributions are not the same for all individuals. Furthermore, while the importance of these factors was not the same for all individuals, neither were they different for all individuals. We identified four relatively distinct subgroups of individuals based on the within-subject factors hypothesized to influence attributions concerning absence. Overall, the results indicate that while illness was the dominant factor in absence decisions for most individuals (roughly 2 out of 3 ), it clearly was not for all. In fact, for one subgroup, while illness exerted a moderately strong positive effect on absence attributions, kinship responsibilities exerted a somewhat stronger effect on attributions.

Taken together, these results indicate support for Johns and Nicholson's (1982) argument that the meaning of absence, and the factors that cause it, is not the same for all individuals. While perhaps the meaning of absence inducing events is not phenomenologically unique to all individuals, our results do suggest some uniqueness between subgroups of individuals. Further work replicating and extending these results, necessarily utilizing withinsubject designs, seems warranted.

Based on the subgrouping of individuals from the cluster analysis, we used betweensubject variables to seek to understand how these subgroups differed. The ANOVAs revealed a number of differences between the subgroups of individuals, and identified several variables that were quite different across the groups. Specific differences between the average levels of between-subjects factors for each subgroup, and profile descriptions of the subgroups, can help us understand how, and perhaps why, the groups are different.

Members of Cluster 1 ( $\underline{n}=30)$, the illness and work demands weak group, were likely to have the highest annual salaries, have the highest organizational tenure, be the oldest, and have among the fewest health complaints. The fact that the illness and work demands factors were weak influences on absence attributions may be due to the fact that these individuals are simply not absent very much. Alternatively, based on their demographic profile, these employees appear to be well-established (e.g., high tenure and annual salaries), suggesting that these employees are not required to explain their absence to anyone in the organization. 
Members of Cluster 2 ( $\underline{n}=62$ ), the illness moderate, kinship responsibilities weak group, earned among the lowest wages, and had relatively lower job tenure compared to their tenure with the organization. Kinship responsibilities may exert a weak influence on attributions for this group due to the fact that these individuals had spouses with whom to share these responsibilities. The moderate impact of illness may be due to the fact that members of this cluster experience a moderate amount of health complaints (compared to the levels of health complaints experienced by members of the other clusters), and these members believe that a moderate number of days absent would trigger punishment by the employer (compared to the numbers expressed by members of the other clusters).

Akin to Cluster 1 , members of Cluster $3(\underline{n}=21)$, the counter cluster, are likely to have the highest annual salaries, and the highest organizational tenure. However, unlike the other clusters, members of Cluster 3 tend to experience the greatest frequency of health complaints, and they believe that they would need to be absent approximately 10 days absent (compared to a range of 16 to 28 for the other clusters) before being punished. We labeled this cluster "counter cluster" because members tended to make internal attributions for kinship responsibilities and personal illness, which stands in contrast to the rationale we presented earlier. It may be the case that members of this cluster experience chronic absenteeism possibly due to burdensome kinship responsibilities and frequent health problems. To the extent that these conditions are recurring, these employees may have reputations for excessive absence. Thus, over time these employees may integrate these conditions as part of their identities, making internal attributions for kinship responsibilities and personal illness when absent.

Members of Cluster $4(\underline{n}=25)$, illness and kinship responsibilities dominant, are predominantly unmarried females, are among the lowest wage earners, and have the lowest job and organizational tenure. The dominance of kinship responsibilities may be due to the fact that many of the cluster members do not have a spouse on whom to rely when dependents are ill. Personal illness was also a dominant factor. This finding makes sense when considering that members of Cluster 4 believed that they would need to absent approximately 28 days before being penalized, and they tended to experience the lowest health complaints. Thus, personal illness may represent a socially desirable excuse for these individuals.

\section{Strengths and Limitations}

A strength of our study lies in the use of control variables and reliance on employees in a work context. Also, collecting data from three sources should mitigate problems due to common method variance. Another strength is based on our duplication of some of the 
scenarios in order to assess the reliability of participants' ratings. Finally, our advance promise of confidentiality and explicit informed consent should have reduced the chance that participants provided socially desirable responses to questions.

One potential limitation is the possibility that the dispositional factors were not conceptually and empirically independent. We believe that our explanations for the influence of each of these factors on attributions concerning absenteeism highlight separate operating mechanisms. Also, a perusal of the zero-order correlations contained in Table 1 reveals that the greatest amount of shared variance between any pair of dispositions is only 4 per cent. Taken together, we are confident that the dispositions included in this study represent distinct sources of attributions concerning absence.

Finally, one might criticize these findings on the grounds that subjects were asked to make absence decisions in a contrived setting rather than in the context in which absence decisions are made -- the field. In particular, it could be argued that there was little resemblance between the context in which we conducted our study and the work context (i.e., our subjects were taking time from their jobs to respond to our survey which contained hypothetical scenarios versus reflecting on their absences from work). While it is true that subjects were asked to make these attributions in a contrived setting, we tried to construct the scenarios to be as realistic as possible and used employees as subjects. Further, the effects of the relatively stable dispositional factors, whose assessment should be unaffected by the study's context, were consistent with our hypotheses. Therefore, the lack of resemblance between the study's context and the context in which attributions concerning absence are typically made makes generalizations to the "real-life" setting stronger (Mook, 1983).

\section{Conclusions}

This study identified absence-inducing events about which employees make attributions, and these results add insights into the meaning of voluntary and involuntary absence to employees. Also, the results demonstrated the importance of dispositions as a source of attributions employees make concerning absence. Future research should attempt to replicate these findings for samples of employees from different populations and settings. Moreover, research that attempts to establish links between dispositions and actual absence events is warranted. Finally, wide variance between individuals in the importance of the factors in absence attributions suggests that the factors that are thought to cause absence do not have equivalent meaning for all individuals, as suggested by Johns and Nicholson (1982). 


\section{References}

Abramson, L. Y., Seligman, M. E. P., \& Teasdale, J. D. (1978). Learned helplessness in humans: Critique and reformulation. Journal of Abnormal Psychology, 87, 49-74.

Alloy, L. B., \& Abramson, L. Y. (1979). Judgment of contingency in depressed and nondepressed students: Sadder but wiser? Journal of Experimental Psychology: General, 108, 441-485.

Atkin, R. S., \& Goodman, P. S. (1984). Methods of defining and measuring absenteeism. In P. S. Goodman, R. S. Atkin, \& Associates (Eds.), Absenteeism: New approaches to understanding, measuring, and managing employee absence (pp. 47-109). San Francisco: Jossey-Bass.

Ballagh, J. H., Maxwell, E. B., \& Perea, K. A. (1987). Absenteeism in the workplace. Chicago: Commerce Clearing House.

Blood, M. R. (1969). Work values and job satisfaction. Journal of Applied Psychology, 53, 456-459.

Bultena, G. L., \& Oyler, R. (1971). Effects of health on disengagement and morale. Aging and Human Development, 2, 142-148.

Burrell, G., \& Morgan, G. (1979). Sociological paradigms and organizational analysis. London: Heinemann Educational Books.

Chadwick-Jones, J. K., Brown, C. A., Nicholson, N., \& Sheppard, C. (1971). Absence measures: Their reliability and stability in an industrial setting. Personnel Psychology, 24, 463-470.

Cohen, J., \& Cohen, P. (1983). Applied multiple regression/correlation analysis for the, behavioral sciences. Hillsdale, NJ: Erlbaum.

Dalton, D. R., \& Perry, J. L. (1981). Absenteeism and the collective bargaining agreement: An empirical test. Academy of Management Journal, 24, 425-431.

Goodman, P. S., \& Atkin, R. S. (1984). Effects of absenteeism on individuals and organizations. In P. S. Goodman \& R. S. Atkin (Eds.), Absenteeism: New approaches to understanding, measuring, and managing absence (pp. 276-321). San Francisco: Jossey-Bass.

Hackett, R. D. (1990). Age, tenure, and employee absenteeism. Human Relations, 43, 601619.

Hackett, R. D., Bycio, P., \& Guion, R. M. (1989). Absenteeism among hospital nurses: An idiographic-longitudinal analysis. Academy of Management Journal, 32, 424-453.

Hammer, T. H., \& Landau, J. C. (1981). Methodological issues in the use of absence data.. Journal of Applied Psychology, 66, 574-581.

Hanushek, E. A., \& Jackson, J. E. (1977). Statistical methods for social scientists. Orlando, FL: Academic Press. 
Hays, W. L. (1981). Statistics (3rd ed.). New York: Holt, Rinehart, \& Winston.

Higgins, R. L., \& Snyder, C. R. (1989). The business of excuses. In R. A. Giacalone \& P. Rosenfeld (Eds.), Impression management in the organization (pp. 73-85). Hillsdale, NJ: Lawrence Erlbaum.

Johns, G., \& Nicholson, N. (1982). The meanings of absence: New strategies for theory and research. In B. M. Staw \& L. L. Cummings (Eds.), Research in organizational behavior (Vol 4, pp. 127-172). Greenwich, CT: JAI Press.

Judge, T. A. (1992). The dispositional perspective in human resources research. In G. R. Ferris \& K. M. Rowland (Eds.), Research in personnel and human resources management (Vol. 10, pp. 31-72). Greenwich, CT: JAl Press.

Judge, T. A., \& Bretz, R. D. (1993). Report on an alternative measure of affective disposition. Educational and Psychological Measurement, 51, 1095-1104.

Judge, T. A., \& Bretz, R. D., Jr. (1992). Effects of work values on job choice decisions. Journal of Applied Psychology, 77, 261-271.

Judge, T. A., \& Watanabe, S. (1993). Another look at the job satisfaction-life satisfaction relationship. Journal of Applied Psychology, 78.

Kennedy, P. (1985). A guide to econometrics. Cambridge, MA: MIT Press.

Keppel, G. (1982). Design and analysis: A researcher's handbook (2nd ed.). Englewood Cliffs, NJ: Prentice-Hall.

Kobasa, S. C. (1979). Stressful life events, personality, and health: An inquiry into hardiness. Journal of Personality and Social Psychology, 37, 1-11.

Lefcourt, H. M. (1991). Locus of control. In J. P. Robinson, P. R. Shaver, \& L. S. Wrightsman (Eds.), Measures of personality and social psychological attitudes (pp. 413-499). New York: Academic Press.

Leigh, P. J. (1991). Employee and job attributes as predictors of absenteeism in a national sample of workers: The importance of health and dangerous working conditions. Social Science \& Medicine, 33, 127-137.

Levenson, H. (1981). Differentiating among internality, powerful others, and chance. In H. M. Lefcourt (Ed.), Research with the locus of control construct (Vol. 1, pp. 15-63). New York: Academic Press.

Martocchio, J. J. (1989). Age-related differences in employee absenteeism: A meta-analytic review. Psychology and Aging, 4, 409-414.

Martocchio, J. J. (1992). The financial cost of absence decisions. Journal of Management, 18, 133-152. 
Martocchio, J. J., \& Harrison, D. A. (1993). To be there or not to be there? Questions, theories, and methods in absenteeism research. In G. R. Ferris (Ed.), Research in Personnel and human resources management (Vol. 11, pp. 259-327). Greenwich, CT: JAI Press.

Martocchio, J. J., \& Judge, T. A. (in press-a). A policy capturing approach to individuals' decisions to be absent. Organizational Behavior and Human Decision Processes.

Martocchio, J. J., \& Judge, T. A. (in press-b). When we don't see eye to eye: Discrepancies between supervisors and subordinates in absence disciplinary decisions. Journal of Management.

Milligan, G. W. (1980. An examination of the effect of six types of error perturbation on fifteen clustering algorithms. Psychometrika, 45, 325-342.

Mirels, H. L., \& Garrett, J. B. (1971). The Protestant Ethic as a personality variable. Journal of Consulting and Clinical Psychology, 36, 40-44.

Mook, D. G. (1983). In defense of external validity. American Psychologist, 38, 379-387.

Morgan, L. G., \& Herman, J. B. (1976). Perceived consequences of absenteeism. Journal of Applied Psychology, 62, 237-240.

Nicholson, N. (1977). Absence behavior and attendance motivation: A conceptual synthesis. Journal of Management Studies, 14, 231-252.

Nicholson, N., \& Johns, G. (1985). The absence culture and the psychological contract Who's in control of absence? Academy of Management Review, 10, 397-407.

Nicholson, N., \& Payne, R. (1987). Absence from work: Explanations and attributions. Applied Psychology: An International Review, 36, 121-132.

Parsons, T. (1952). The social system. London: Tavistock.

Paulhus, D. L. (1984). Two-component models of socially desirable responding. Journal of Personality and Social Psychology, 46, 598-609.

Paulhus, D. L. (1986). Self-deception and impression management in test responses. In A. Angleitner \& J. S. Wiggins (Eds.), Personality assessment via questionnaire (pp. 143165). New York: Springer-Verlag.

Paulhus, D. L. (1991). Measurement and control of response bias. In J. P. Robinson, P. R. Shaver, \& L. S. Wrightsman (Eds.), Measures of personality and social psychological attitudes (pp. 17-59). San Diego, CA: Academic Press.

Paulhus, D. L., \& Reid, B. (1991). Enhancement and denial in social desirable responding. Journal of Personality and Social Psychology, 60, 307-317.

Peterson, C., \& Seligman, M. E. P. (1984). Causal explanations as a risk factor for depression: Theory and evidence. Psychological Review, 91, 347-374. 
Peterson, C., Semmel, A., von Baeyer, C., Abramson, L. Y., Metalsky, G. L, \& Seligman, M. E. P. (1982). The attributional style questionnaire. Cognitive Theory and Research, 6 , 287-300.

Quinn, R. P., \& Staines, G. (1979). Quality of Employment Survey, 1973-1977: Panel. Ann Arbor, MI: Inter-University Consortium for Political and Social Research.

Rhodes, S. R., \& Steers, R. M. (1990). Managing employee absenteeism. Reading, MA: Addison-Wesley.

Rokeach, M. (1973). The nature of human values. New York: Free Press.

Rosenthal, R. (1979). Arbitral standards for absenteeism discharges. Labor Law Journal, 30, $732-740$

Roth, D. L., \& Ingram, R. E. (1985). Factors in the self-deception questionnaire: Associations with depression. Journal of Personality and Social Psychology, 48, 243251.

Roth, D. L., Snyder, C. R., \& Pace, L. M. (1986). Dimensions of favorable self-presentation. Journal of Personality and Social Psychology, 51, 867-874.

Rotter, J. B. (1954). Social learning and clinical psychology. Englewood Cliffs, NJ: Prentice-Hall.

Rotter, J. B. (1966). Generalized expectancies for internal versus external control of reinforcement. Psychological Monographs: General and Applied, 80, (Whole No. 609).

Rushmore, C. H., \& Youngblood, S. A. (1979). Medically-related absenteeism: Random or motivated behavior? Journal of Occupational Medicine, 21, 245-250.

Sackeim, H. A., \& Gur, R. C. (1979). Self-deception, other-deception, and self-reported psychopathology. Journal of Consulting and Clinical Psychology, 47, 213-215.

Salancik, G. R., \& Pfeffer, J. (1978). A social information processing approach to job attitudes and task design. Administrative Science Quarterly, 23, 224-251.

Seligman, M. E. P. (1975). Helplessness: On depression, development, and death. San Francisco: Freeman.

Smulders, P. G. W. (1980). Comments on employee absence/attendance as a dependent variable in organizational research. Journal of Applied Psychology, 65, 368-371.

Snyder, C. R., \& Higgins, R. L. (1988). Excuses: Their effective role in the negotiation of reality. Psychological Bulletin, 104, 23-35.

Staw, B. M., \& Oldham, G. R. (1978). Reconsidering our dependent variables: A critique and empirical study. Academy of Management Journal, 21, 539-559.

Steers, R. M., \& Rhodes, S. (1978). Major influences on employee attendance: A process model. Journal of Applied Psychology, 63, 391-407.

Taylor, S. E. (1989). Positive illusions: Creative self-deception and the healthy mind. New York: Basic Books. 
Tucker, L. A. Aldana, S. G., \& Friedman, G. (1990). Cardiovascular fitness and absenteeism in 8,301 employed adults. American Journal of Health Promotion, 5, 140146.

Ward, J. H. (1963). Hierarchical grouping to optimize an objective function. Journal of the American Statistical Association, 58, 236-244.

Watson, D., \& Clark, L. A. (1984). Negative affectivity: The disposition to experience aversive psychological states. Psychological Bulletin, 96, 465-490.

Watson, D., Clark, L. A., \& Tellegen, A. (1988). Development and validation of brief measures of positive and negative affect: The PANAS scales. Journal of Personality and Social Psychology, 54, 1063-1070.

Wetzel, J. R. (1990). American families: 75 years of change. Monthly Labor Review, 113, 4-13. 


\section{Author Notes}

The authors contributed equally to this manuscript. Partial funding for this study was provided by the School of Industrial and Labor Relations, and the Center for Advanced Human Resource Studies, Cornell University. Portions of this paper will be presented at the Florida State Symposium on Attribution Theory, June 3-4, 1994, Tallahassee, FL.

Correspondence regarding this manuscript should be addressed- to Timothy A. Judge, Department of Human Resource Studies, 393 Ives Hall, Cornell University, Ithaca, NY 14853-3901. 
Table 1

\section{Means (M), Standard Deviations (SD), and Intercorrelations of Study Variables}

\begin{tabular}{|c|c|c|c|c|c|c|c|c|c|c|c|c|c|c|c|c|c|c|c|}
\hline & $M$ & SD & 1 & 2 & 3 & 4 & 5 & 6 & 7 & 8 & 9 & 10 & 11 & 12 & 13 & 14 & 15 & 16 & $17 \quad 18$ \\
\hline 1. External attribution & 2.77 & 1.66 & - & & & & & & & & & & & & & & & & \\
\hline 2. Number of dependents & 0.69 & 0.98 & 03 & - & & & & & & & & & & & & & & & \\
\hline 3. Race & 0.02 & 0.12 & 06 & 04 & - & & & & & & & & & & & & & & \\
\hline 4. White-collar occupation & 0.27 & 0.44 & 02 & 11 & 06 & - & & & & & & & & & & & & & \\
\hline 5. Organization tenure & 11.41 & 7.90 & 06 & -20 & -05 & 17 & - & & & & & & & & & & & & \\
\hline 6. Age & 46.00 & 10.67 & -02 & -50 & -15 & -03 & 36 & - & & & & & & & & & & & \\
\hline 7. Pressing work & 0.47 & 0.50 & 05 & 00 & 00 & 00 & 00 & 00 & - & & & & & & & & & & \\
\hline 8. Illness & 1.10 & 0.83 & 25 & 00 & 00 & 00 & -00 & 00 & 05 & - & & & & & & & & & \\
\hline 9. Break in work week & 0.53 & 0.50 & -02 & 00 & 00 & 00 & 00 & 00 & $-06-$ & -05 & -- & & & & & & & & \\
\hline 10. Kinship responsibilities & 0.47 & 0.50 & 10 & -00 & 00 & 00 & 00 & 00 & $06-$ & -11 & -06 & - & & & & & & & \\
\hline 11. Life controlled by chance* & ${ }^{*} 17.09$ & 5.08 & 04 & -01 & -09 & 11 & 05 & 02 & 00 & 00 & 00 & 00 & - & & & & & & \\
\hline 12. Protestant work ethic* & 37.24 & 6.18 & -08 & 01 & -10 & 05 & 01 & 05 & 00 & 00 & 00 & 00 & -01 & - & & & & & \\
\hline $\begin{array}{l}\text { 13. Tendency to make } \\
\text { excuses }\end{array}$ & 62.16 & 7.69 & 06 & -01 & -01 & -20 & -19 & 05 & 00 & 00 & 00 & 00 & -08 & 04 & - & & & & \\
\hline 14. Learned helplessness & 37.53 & 8.27 & 11 & -08 & 00 & 09 & -10 & 03 & 00 & 00 & 00 & 00 & -02 & -08 & -01 & - & & & \\
\hline 15. Negative affectivity & 17.49 & 5.23 & -06 & -03 & -07 & 04 & 13 & 01 & 00 & 00 & 00 & 00 & 16 & -05 & -13 & -07 & - & & \\
\hline 16. Physical symptoms* & 15.35 & 3.78 & 06 & -11 & -12 & -01 & -01 & 05 & 00 & 00 & 00 & 00 & 20 & -11 & -12 & -04 & 10 & & \\
\hline 17. Internal locus of control & 41.04 & 5.81 & -09 & -03 & -04 & -09 & 15 & 02 & 00 & 00 & 00 & 00 & 04 & 15 & -08 & -20 & -19 & -07 & - \\
\hline 18. Self-deception & 27.54 & 8.26 & 09 & 20 & 07 & -20 & -16 & -06 & -00 & 00 & 00 & 00 & -12 & -12 & 14 & 06 & -12 & $-20-$ & -18 \\
\hline
\end{tabular}

Notes: Decimals are omitted from correlations; correlations greater than .05 are significant at the .01 level (two-tailed); number of observations $=4,136$; number of subjects $=141$; * reported by significant other. 
Table 2

Regression Estimates Predicting External Attributions Regarding Absence

Variable

Unstandardized

Coefficient

Standard

Error

T-Value

Demographic Variables

Number of dependents

Race

$+.008$

.006

$+1.31$

$+.002$

.005

$+3.58^{\text {** }}$

White-collar occupation

$-.001$

.006

$-0.12$

Organization tenure

$+.051$

.006

$+8.43^{* *}$

Age

$-.020$

.007

$-3.02^{* *}$

Within-Subjects Factors

Pressing work

$+.011$

.005

$+2.09$

Illness

$+.094$

.005

$+17.85^{\star *}$

Break in work week

$+.001$

.005

$+0.22$

Kinship responsibilities

$+.045$

.005

$+8.44^{\text {** }}$

\section{Dispositional Variables}

Protestant Work Ethic

$-.013$

.005

$-2.46^{*}$

Self-deception

$+.029$

.006

$+4.93^{\text {** }}$

Negative affectivity

$-.028$

.006

$-5.01^{* *}$

Tendency to make excuses

$+.028$

.006

$+5.07^{\text {** }}$

Life controlled by chance

$+.021$

.005

$+3.81^{\text {** }}$

Internality

$-.027$

.006

$-4.58^{* *}$

Learned helplessness

$+.038$

.005

$+6.89^{\text {** }}$

Health complaints

$+.033$

.006

$+5.78^{\star *}$

Notes: Estimates are generalized least squares; Life controlled by chance, Protestant Work Ethic, and health complaints were reported by significant others; ${ }^{*} p<.01$ (one-tailed); ${ }^{* *} p<.001$ (one-tailed). 
Table 3

Regression Weights of Within-Subject Factors by Cluster

\begin{tabular}{lcccc} 
& \multicolumn{4}{c}{ Cluster } \\
Variable & 1 & 2 & 3 & 4 \\
\hline Kinship Responsibilities & .005 & $.112^{* *}$ & $-.079^{*}$ & $.489^{* *}$ \\
Work Demands & .060 & .017 & $.124^{* *}$ & $-.053^{*}$ \\
Break in Work Week & -.040 & .004 & .038 & .021 \\
Illness & $.126^{* *}$ & $.421^{* *}$ & $-.229^{* *}$ & $.408^{* *}$ \\
R & $.151^{* *}$ & $.425^{* *}$ & .261 & $.597^{* *}$ \\
Adjusted R & .018 & .179 & .062 & .352 \\
Number of Subjects & 30 & 62 & 21 & 25
\end{tabular}

Note: ${ }^{\star} p<.05 ;{ }^{* *} p<.01$; estimates are standardized regression coefficients. 
Table 4

\section{Means of Between-Subjects Variables for Each Cluster}

Cluster

\begin{tabular}{|c|c|c|c|c|}
\hline Variable & 1 & 2 & 3 & 4 \\
\hline Number of dependents & 0.63 & 0.61 & 0.81 & 0.72 \\
\hline Sex & $0.33^{d}$ & $0.32^{d}$ & $0.43^{d}$ & $0.12^{\mathrm{a}, \mathrm{b}, \mathrm{c}}$ \\
\hline Marital status & 0.23 & $0.21^{d}$ & 0.33 & $0.60^{\mathrm{b}}$ \\
\hline White-collar occupation & 0.33 & $0.23^{c}$ & $0.43^{\mathrm{b}, \mathrm{d}}$ & $0.16^{c}$ \\
\hline Annual salary & $36087^{b, d}$ & $24394^{a}$ & 34633 & $23675^{a}$ \\
\hline Hours worked per week & $40.7^{c}$ & $40.5^{c}$ & $36.7^{\mathrm{a}, \mathrm{b}}$ & 37.9 \\
\hline Organization tenure & $12.7^{d}$ & 11.5 & 12.1 & $8.6^{\mathrm{a}}$ \\
\hline Job tenure & $11.7^{\mathrm{b}, \mathrm{d}}$ & $8.5^{\mathrm{a}, \mathrm{c}}$ & $12.0^{\mathrm{b}, \mathrm{d}}$ & $6.8^{\mathrm{a}, \mathrm{c}}$ \\
\hline Education level & $3.0^{d}$ & $2.9^{d}$ & 3.0 & $3.6^{a, b}$ \\
\hline Age & 48.4 & 46.4 & 45.0 & 43.7 \\
\hline Life controlled by chance* & 18.6 & $16.9^{c}$ & $17.7^{\mathrm{b}, \mathrm{d}}$ & $15.2^{c}$ \\
\hline Protestant Work Ethic* & 37.6 & 36.5 & 39.0 & 37.0 \\
\hline Learned helplessness & 38.0 & 37.4 & 39.7 & 35.9 \\
\hline Negative affectivity & 18.5 & 17.4 & 17.8 & 16.3 \\
\hline Health complaints* & $14.6^{c}$ & $15.8^{d}$ & $16.7^{\mathrm{a}, \mathrm{d}}$ & $14.3^{\mathrm{b}, \mathrm{c}}$ \\
\hline Internal locus of control & 40.5 & 40.5 & 41.1 & 42.5 \\
\hline Self-deception & 28.3 & 27.3 & 27.2 & 26.8 \\
\hline Penalties for absence & 16.0 & 19.6 & $10.2^{d}$ & $28.7^{c}$ \\
\hline
\end{tabular}

Notes: ${ }^{a}$ significantly different from Cluster $1 ;{ }^{b}$ significantly different from Cluster 2;

${ }^{c}$ significantly different from Cluster $3 ;{ }^{d}$ significantly different from Cluster $4 ;$; significant other report 